\title{
DEVELOPMENT OF A MULTI-OBJECTIVE MODEL WITH MULTIPLE ALLOCATION OF LIMITED CAPACITY IN TERMS OF UNCERTAINTY FOR LOCATION AXES
}

\author{
Hoonaz Shamayi Irani \\ Department of Industrial Engineering,Parand Branch, Islamic Azad University, Parand, Iran \\ Davood Jafari \\ Department of Industrial Engineering,Parand Branch, Islamic Azad University, Parand, Iran
}

\begin{abstract}
One of the topics of hub location is new facility location that has recently been the focus of many researchers. Hub location issues generally arise in the network transport and communications. Role of a transition point plays axial point where incoming traffic from this source together and sent to the other focal point or the traffic is divided into several arteries that are directed towards other purposes. Due to the uncertainty in the current situation is one of the most difficult and the most important responsibilities of project managers are considering the uncertainties in modeling. How to insert the uncertainty in the model and solving different issues impact on the performance and success of the project is the main goal of the current study. The current study is applied and exploratory research which introduces a Mathematical Model and analyzes it using Gomez Software. In the Methodology of this study, some Mathematical parameters have been used as follows:

$\mathrm{N}, f_{k}, d_{i k}, d_{k l}, d_{l j}, w_{i j}, o_{i}, x, \delta, \alpha, C_{k}, g_{j}, t_{i j}, \beta_{j}, \alpha_{2}, T^{t}, \varepsilon^{t}, X_{K}, y_{l k}^{i}, u_{i k}, v_{l j}^{i}, R_{i j k l}$. Which have been discussed in details in Methodology part inside the paper. According to the mathematical model of this study, taking into account the capacity and the constraints, the multiple allocation has been posted, the limitations and the service level has been analyzed. Further, the introduced Mathematical model is validated by Gomez Software. In the current study, the effectiveness of the written version of the model prepared by the Railways Organization of the Islamic Republic of Iran has been solved and the optimal locations for the hub are introduced and the rest of the points specified by the hub connected to the hub. Finally, a network hub has been shown schematically.
\end{abstract}

Keywords: Location Hub - Location Facilities - Uncertainty - Multiple Allocation - robust Optimization

\section{INTRODUCTION}

Facility Location is known in the field of applied research. Published numerous articles and research evidence on this claim. Issues hub location for many applications in modern transport and communication systems in the past two decades have been of great importance. Network design on many issues of transport and communications major issue because a large impact on efficiency and economic costs of the service. In some cases, a direct correlation between non-hub and it is very expensive goods from other nodes that are called hub.

For this reason instead of using a direct connection to source indirect connections (connection to hub) to be handled. Thus can be used from economies of scale. In such cases the purpose of the network is allowed to move to the flow of goods among non-hub are hub by nodes.

\section{GENERAL DEFINITION OF THE TOPICS DISCUSSED: HUB LOCATION}

Submit Date: 10.05.2016, Acceptance Date: 25.06.2016, DOI NO: 10.7456/1060JSE/004 Copyright (C) The Turkish Online Journal of Design, Art and Communication 
One of the new issues that have been raised in the area of facility location problems, the problem is hub location. The most fundamental problem in the transport, logistics and communications network streams from points of origin to destination. In the design of hub network, when needed the points of origin and destination, but the current value communicate directly available everywhere, or is impossible or expensive, hub location is used. Problem of hub location of the transfer of goods from origin to destination where instead of a direct connection between any two points of origin and destination of goods transported by tourists.

Can be placed to the center 5 key role:

1. Collect small stream

2. Transformation of the small to the large

\section{Current transmission}

4. Transformation of the large flow of small

\section{Current distribution of small}

In general purpose of possibility of moving the intermediate nodes in hub network to reduce costs.

Problems location pivot points, depending on the restrictions on the flow of the network or cannot have the capacity or non-capacity. Purpose of network of focal points by taking decisions on capacity effective capacity of focal points and the connections between them, because the transmission capacity of focal points and the connections between them are costly and effective capacity will lead to cost savings.

\section{ROBUST OPTIMIZATION METHOD}

Uncertainty can be described as the difference between the amounts of information required to carry out an activity defined as the amount of information available.

A lack of planning restrictions in random or inconsistent priorities and risk management decision-makers. A planning improved named based with the ability to deal with the lack of planning has been developed.

With regard to the merits of flexible optimization modeling allowed the based, little is expected that this technique can be a valid methodology for uncertainty in the real world presents logistical problems. In other words, simply implement this method enables decision makers to logistics system without complex planning procedures, control and manage.

robust optimization method has 3 approach based on the sensitivity, scenarios and mini Max. Two major flaws based scenario-based optimization (1) how to determine the number of scenarios to achieve based response is required. (2) This scenario describes how to create and assign probabilities to them. For this reason research in connection with the limitations of this approach have been conducted. For example, the reduced variance methods can be used to generate scenarios.

Variability model: variability model of the parameters, standard deviation, variance and other measures to control the distribution of the target amount. The purpose is to minimize total cost and reduce the difference between the purposes under different scenarios.

Research in the field of location hub single allocation began by Okelly [15]. OKelly developed the first mathematical model for problem middle Model and Campbell [3] proposed a linear modeling for it. 
Other researchers have also developed mathematical models to solve this problem for many innovative way round this problem is seen in literature. The first algorithms for the solution proposed by Okelly [15] .In both his innovative methods, all possible choices are the places p- hub. In the first initiative, demand nodes closest to hub dedicated and innovative approach II (based on the objective function value) close to the node demand hub best two are selected.

Serra et al. [17] have studied based on problem location of air transportation. They have hub as modeling systems queue. The formula for the probability that the number of customers in the system that is used later to offer capacity constraints. Fukushima [7] model for multiple allocation of problem limited capacity of their hub location. They include model capacity constraints on both axes and their edges.

Yaman and Carello [19] considered problem hub location with several means of binding capacity as well as capacity constraints on the flow of looked at the pivot point, where only hub cost of establishment and cost of the connection. In this paper, the Tabu search algorithm is used. Hung and Wang [10] considered robust optimization model for location hub issue in a state of unlimited capacity nodes and using multiobjective genetic algorithms to solve their problem. Yang investigated the issue dealt with in the field of aviation. Random demand and problem intended as a randomized two-step plan is modeled. Equivalent deterministic problem is solved by taking 3 scenarios. Direct transfer of non- hub is permitted. A case study in connection with the air transport industry in Taiwan and China that there is only one location. Sim et al. [18] considered in his article travel time as possible and non-deterministic and heuristic algorithms to solve problem. In this paper, a limit that ensures the possibility of total travel time along a path that is less than the given time limit, the amount of data is larger. Contreras et al . [4] have examined Multiple random allocation unlimited capacity problem location hub (check the same time, demand and cost of setting up a non-definitive), the uncertainty linked to the demands and costs of transportation. They have shown that problems with random demand and the cost of transportation related crashes that are a certain equivalence. Their algorithm for this problem with the cost of transportation offered independent random. Mohammadi et al. [13] hub on the location of the queue system has been studied in a limited capacity axles.

Makui et al. [12] for the limited capacity of the location hub multi-objective optimization model provides scenario-based firm that uncertainty to the demand of each node and the time required for the processing of the product attributed. Including research papers, articles Eydi et al. [6] is an innovative technique using genetic algorithms to solve the fuzzy front hub Msaalh offered.

Bashiri et al. [1] in their article a non-deterministic model of hierarchical hub for problem location in which the transit time as possible is considered. The objective function to minimize the shipping cost is also a potential constraint on the time shift in the network model.

Davari et al. [5] to review the location hub, taking into account demand for non-deterministic and fuzzy paid. Bozorgi et al. [2] in their article a multilevel hierarchical hub offered the highest level of the central hub and the second and third levels are hubs and points of demand. In this article is intended for all the capacity constraints and all communications between locations are also limited and the delivery time limits are also included in the model.

Jelodari [11] in their article an objective model for location - routing offered that first objective represents a purpose minimizing the costs and second represent the minimum the largest position in any way responsible for delivery time. So that in addition to increased efficiency, increased productivity and customer satisfaction is achieved.

Mohammadi et al. [14] problem location hub as a function of environmental costs of air pollution and noise pollution modeling their machines and using an innovative approach and a simulated annealing

Submit Date: 10.05.2016, Acceptance Date: 25.06.2016, DOI NO: 10.7456/1060JSE/004 
algorithm imperialist competition a new solution developed to solve some real size. Finally some computational tests performed on known data collection and the effectiveness of the model is depicted. Habibzadeh Bukani [9] in their article a simple allocation of limited capacity and multi- hub location to the optimum approach is based modeling.

Bukani [9] their Model, and is considered the single-minded in the objective function minimizing total cost, and capacity constraints in the model is included. In fact his innovations in research capacity constraints in terms of uncertainty remains. Finally, Bukani [9] model on data collection Aircraft Islamic Republic has implemented.

In the field hub location robust optimization, the article by Huang [10] is presented. He based this model to minimize problem total cost of transportation, regardless of the capacity constraint model using genetic algorithms to solve the multi-objective. Makuie [12], taking into account capacity constraints for Huang model problem expanded. Based model presented in this article for an example using the weighting method is solved.

The third article based hub location problem with capacity constraints by Rostami [16] is presented. Finally, a model in Iran and it has solved using goal programming. Ghasemi [8] in 2013 based model to optimize problem capacity of the hub when the hubs are provided. It has two objectives are. The first objective is to minimize construction costs and the cost of shipping.

All the Following Tables' Titles have been inserted Above the tables, and the Figure's Title has been inserted Below the figures.

Table 1. Literature Review

\begin{tabular}{|c|c|c|c}
\hline Topic & Year & Author & Row \\
\hline $\begin{array}{c}\text { Using the queuing system M/D/C in the } \\
\text { unlimited capacity axles }\end{array}$ & 2003 & Serra et al & 1 \\
\hline $\begin{array}{c}\text { Uncertain demand for and use of a } \\
\text { randomized two-step plan }\end{array}$ & 2009 & Yang & 2 \\
\hline $\begin{array}{c}\text { Travel time for non-deterministic and } \\
\text { heuristic algorithm to solve the model }\end{array}$ & 2009 & Sim et al & 3 \\
\hline $\begin{array}{c}\text { Uncertain demand for and cost of setting up } \\
\text { multiple allocation unlimited capacity }\end{array}$ & 2011 & Contreras et al & 4 \\
\hline $\begin{array}{c}\text { Using the queuing system M/D/C in a limited } \\
\text { capacity axles }\end{array}$ & 2011 & Mohammadi et & al \\
\hline $\begin{array}{c}\text { P- model hub optimization based on the } \\
\text { limited capacity of axles }\end{array}$ & 2012 & Makui al & 6 \\
\hline $\begin{array}{c}\text { Allocation Model based hub with capacity } \\
\text { constraints }\end{array}$ & 2012 & Rostami & 7 \\
\hline
\end{tabular}

Submit Date: 10.05.2016, Acceptance Date: 25.06.2016, DOI NO: 10.7456/1060JSE/004 Copyright (C) The Turkish Online Journal of Design, Art and Communication 


\begin{tabular}{|c|c|c|c}
$\begin{array}{c}\text { Robust optimization and stochastic } \\
\text { programming simple and multiple allocation } \\
\text { unlimited capacity }\end{array}$ & 2012 & Alumur et al & 8 \\
\hline $\begin{array}{c}\text { Random mix of planning and scheduling } \\
\text { opportunity in location hub issues }\end{array}$ & 2014 & $\begin{array}{c}\text { Mohammadi et } \\
\text { al }\end{array}$ & 9 \\
\hline $\begin{array}{c}\text { based scenario-based optimization in } \\
\text { allocation models Simple and multiple } \\
\text { limited capacity with the launch of hub } \\
\text { uncertain costs }\end{array}$ & 2014 & Habibzade et al & 10 \\
\hline $\begin{array}{c}\text { A model based two objective with capacity } \\
\text { constraints }\end{array}$ & 2015 & Shamaei et al & 11 \\
\hline
\end{tabular}

Switching between hubs is considered a type of aircraft is the result of fixed cost. The second objective is to maximize the utility of the aircraft has been noted. Habibzadeh [9] in the uncertain environment using search optimization approach based on parameters such as cost of setting up hub uncertainty and capacity to meet hub demand nodes examined. In Table following articles in connection with the review of the uncertainty in the location hub issues in the literature review are:

Taking a look at the literature review was to realize that extensive research has been done on the allocation of the multi- hub location, there are also a few articles in addition to multiple allocations, constraints such as capacity constraints have also been added.

Since in all previous articles multiple allocation under uncertainty and cost of setting up hub parameters such as capacity and ... One objective is to be taken into account in the study's second objective function with the theme of minimizing the delay and the penalties it is added to the model and in the two abovementioned purpose limitation is also included in the model which ensures the displacement of the threshold $\mathrm{T}$ with probability $1-\varepsilon$ be lower. Research and mentioned model, on data railway Islamic Republic implemented.

\section{METHODOLOGY}

\section{DEFINE THE PROBLEM}

In this sector allocation model we introduce multi- hub location problem limited capacity. The purpose of this model how to allocate the non-driven demand hub communication and minimize the costs imposed on network-centric. In this model, each node can only apply to the non-hub axles created through networking, security and communication between axes of the other part of send network.

Based on this description, the cost of applying any non- hub node connected to its own hub, called the cost of collection. Demand associated with each node when hub node is sent through hub network to other axes that are all connected to each other to be sent. This makes the cost of handling and transmission network, which it referred to as transfer fee.

Finally demand for primary node that was sent to the hub and the hub of the other topics were on the network, all communication between the axes created through the network across the network to other non- hub flows freely distributed. Therefore cost for this current distribution network has been created, called the cost of distribution. 
Each hub for it in the network a fixed cost, depending on the volume of input demand and send it across the network takes different values per hub. Finally models fixed costs for the launch and deployment of axes created considers that the fixed cost hub startup called. Purpose of the allocation model, as was said non-driven axles and minimizing the total cost of building the network.

\section{SYMBOLS AND SIGNS USED IN MATHEMATICAL MODEL COLLECTIONS}

$\mathrm{N}$ : Set the distance and flow between network nodes $N=\{1,2 \ldots 51\}$

(Collections: $i, j, k$ and $l$ also elected from the same data set.)

\section{PARAMETERS}

$f_{k}$ : fixed startup costs for hub k nodes

$d_{i k}$ : Are non- hub nodes $i$, of hub .k, assume that $d_{i i}=1$, the triangle inequality is established.

$d_{k l}$ : Axial distance $k$, the hub 1

$d_{l j}$ : Axial distance $l$, of non- hub node $\mathrm{j}$

$w_{i j}$ : apply non- hub nodes $i$, the non- hub node $\mathrm{j}$

$o_{i}$ : Total flow that is $i$ originating node. $\left(o_{i}=\sum_{j \in n} w_{i j}\right)$

$x$ : Coefficient reducing the cost of collection per unit of flow per unit distance ${ }^{x}=1$

$\delta$ : reduce the cost of distribution rate per unit of flow per unit distance $\delta=1$

$\alpha$ : reduce the cost of transfer coefficient per unit flow per unit distance between the axles. We assume that the coefficients of both the collection and distribution expense ratio is smaller.

$C_{k}$ : flow capacity of each hub k

$g_{j}$ : Penalties for delay

$t_{i j}$ : Time transition from $\mathrm{i}$ to $\mathrm{j}$

$\beta_{j}$ : Promised delivery point $\mathrm{j}$

$\alpha_{2}$ : The coefficient reducing transmission time from $\mathrm{i}$ to $\mathrm{j}$

$T^{t}$ : preset threshold

$\varepsilon^{t}:$ Service Level

\section{DECISION VARIABLES}

If the node $k$ to be selected as the hub:

$X_{K}=\left\{\begin{array}{l}0 \\ 1\end{array}\right.$ 
Otherwise:

Similarly, if $X_{k}=1$ which means that the node is selected as the focus $k$.

$y_{l k}^{i}$ : The flow of the starting node $i$ and through axes $k$ and $l$ in Network should circulate intellectual opportunities. $\left(Y_{i k l} \geq 0\right)$ For $y_{l k i}$ that conditions.

$u_{i k}$ : Total current directly from non- hub node $i, k$ hub has been sent.

$v_{l j}^{i}$ : indicates that the current node $i$, started by hub $l$, to the non- hub node $j$

$R_{i j k l}$ : If a path from point $\mathrm{i}$ to $\mathrm{j}$, through axes $\mathrm{k}$ and $\mathrm{l}$, there is a 1 , otherwise zero.

$\sum_{i \in n} \sum_{l \in n} \sum_{j \in n} \delta d_{l j} v_{i j}^{i}++\sum_{i \in n} \sum_{k \in n} \sum_{l \in n} \alpha d_{k l} y_{k l}^{i}+\sum_{i \in n} \sum_{k \in} x d_{i k} u_{i k} \quad \min \sum_{k \in n} f_{k} x_{k}$

$\operatorname{MinZ}=\sum_{j} g_{j} \sum_{i} \sum_{k} \sum_{l}\left(A_{i j k l}-\beta_{j}\right)$

S.T.

$\sum_{k \in n} u_{i k}=O_{i}$

$\sum_{l \in n} v_{l j}^{i}=w_{i j}$

$\sum_{l \in n} y_{k l}^{i} \leq u_{i k}$

$u_{i k} \leq O_{i} x_{k}$

$v_{i j}^{i} \leq w_{i j} x_{l}$

$\sum_{i \in n} u_{i k} \leq c_{k} x_{k}$

$\sum_{l \in n} y_{k l}^{i}-\sum_{l \in n} y_{l k}^{i}=u_{i k}-\sum_{j \in n} v_{k j}^{i}$

$A_{I J K L}=\left(t_{i k}+t_{k l}+t_{l j}\right) R_{i j k l}$

$p\left\{\sum\left(t_{i j}^{k l}+\alpha_{2} t_{j l}^{k l}\right) R_{i j k l} \leq T^{t}\right\} \geq \varepsilon^{t}$

$y_{k l}^{i}, u_{i k}, v_{j l}^{i} \geq 0$

\section{ANATOMY MODEL}

First objective function: The term first $\sum_{k \in n} f_{k} x_{k}$ represents total fixed costs based setup. The term $\sum_{i \in n} \sum_{k \in n} \sum_{l \in n} \alpha d_{k l} y_{k l}^{i}$ total cost current transmission shows.

The third term $\sum_{i \in n} \sum_{k \in} x d_{i k} u_{i k}$ show total costs of collecting current. Finally term fourth $\sum_{i \in n} \sum_{l \in n} \sum_{j \in n} \delta d_{l j} v_{i j}^{i}$ represents the sum of the cost of flow distribution in the network. Objective function minimizes the sum of all these phrases. 
The second objective function: Represents the minimum delay time (distance traveled in a given time) and the penalties for the delay in receiving in destination.

\section{LIMITATIONS}

Equation 1 all streams have been collected in hub equation 2 indicates that all of the axes are distributed. Equations 3 and 4 and 5 are consistent limits that define the variables are significant. Equation 6 restricts the flow capacity of each node. Limitations 7 is divergence Limitations underway. Limitations 8, arrival time specifies that time limit is 9 ensures mobility with the possibility of $1-\varepsilon$, from time $T$ is less than the threshold.

\section{THE PROPOSED MODEL UNCERTAINTY NODES CAPACITY}

In this capacity nodes is uncertain scenarios $\Omega=\{1,2, \ldots, \mathrm{s}\}$ estimates. This section based in using optimization methods to formulate the issue under consideration to reduce the effects of fluctuations in the capacity of the nodes in the future is discussed. The following mixed integer programming model is presented in terms of uncertainty.

\section{Table. 2. based optimization model parameter variables}

Parameter

\begin{tabular}{|c|l}
\hline \multicolumn{1}{|c|}{$C_{k}^{s}$} & The flow capacity of each hub $k$ under Scenario S \\
\hline Variable & $\begin{array}{l}\text { The flow of nodal } i \text { start and through axes } k \text { and } l \text { under scenario s on the network to } \\
\text { circulate. }\left(y_{k l i} \geq 0\right) \text { for } y_{l k i} \text { the same conditions prevail. }\end{array}$ \\
\hline$y_{l k}^{i s}$ & Total current non hub directly of $i k$ under scenario s is sent to the hub. \\
\hline$u_{i k}^{S}$ & $\begin{array}{l}\text { Indicative of a movement that has started from node } i \text { and through hub } l \text { to the non- } \\
\text { hub node } j \text { under scenario s }\end{array}$ \\
\hline$v_{l j}^{i s}$ & $\begin{array}{ll}\text { If the node is selected as the hub } k \text { under scenario s: } \\
\text { otherwise: }\end{array}$ \\
\hline $\mathbf{0}$
\end{tabular}

$\operatorname{Min} O B J 1=\sum_{s \in \Omega} p^{s} z_{1}^{s}+\sum_{s \in \Omega} p^{s}\left|z_{1}^{s}-\sum_{s \in \Omega} p^{s^{\prime}} z_{1}^{s^{\prime}}\right|$

Min $O B J 2=Z_{2}$

S.T. 


$$
\begin{aligned}
& Z_{1}^{s}=\sum_{k \in n} f_{k} x_{k}^{s}+\sum_{i \in n} \sum_{k \in} x d_{i k} u_{i k}^{s}+\sum_{i \in n} \sum_{l \in n} \sum_{j \in n} \delta d_{l j} v_{l j}^{i s}+\sum_{i \in n} \sum_{k \in n} \sum_{l \in n} \alpha d_{k l} y_{k l}^{i s} \\
& Z_{2}=\sum_{j} g_{i} \sum_{k} \sum_{l}\left(A_{i j k l}-\beta_{j}\right) \\
& \sum_{k \in n} u_{i k}^{s}=O_{i} \\
& \sum_{l \in n} v_{l j}^{i s}=w_{i j} \\
& \sum_{l \in n} y_{k l}^{i s} \leq u_{i k}^{s} \\
& u_{i k} \leq O_{i} x_{k s} \\
& v_{l j}^{i s} \leq w_{i j} x_{l s} \\
& \sum_{i \in n} u_{i k}^{s} \leq x_{k}^{S} x_{k}^{s} \\
& \sum_{l \in n} y_{k l}^{i s}-\sum_{l \in n} y_{l k}^{i s}=u_{i k}^{s}-\sum_{j \in n} v_{k j}^{i s} \\
& A_{I J K L}=r_{i}+\left(t_{i k}+t_{k l}+t_{l j}\right) R_{i j k l} \\
& \left.p\left\{\sum_{i j}^{k l}+\alpha_{2} t_{j l}^{k l}\right) R_{i j k l} \leq T^{t}\right\} \geq \varepsilon^{t}
\end{aligned}
$$

With regard to the question of the objective function that includes the absolute value that causes the problem is nonlinear. For the linear relationship of $\mathrm{Yu}$ and $\mathrm{Li}$ (2000) [21], the definition of a positive variable deviation $\theta^{s}$ used that form linear objective function of time as follows:

$$
\begin{aligned}
& \text { Min } O B J 1=\sum_{s \in \Omega} p^{s} z_{1}^{s}+\sum_{s \in \Omega} p^{s}\left|z_{1}^{s}-\sum_{s \in \Omega} p^{s^{\prime}} z_{1}^{s^{\prime}}\right| \\
& \text { Min } Z=\sum_{s \in \Omega} p^{s} z_{1}^{s}+\sum_{s \in \Omega} p^{s^{s}}\left[\left(z_{1}^{s}-\sum_{s \in \Omega} p^{s^{\prime}} z_{1}^{s^{\prime}}\right)+2 \theta^{s}\right] \\
& -\theta^{s}-z_{1}^{s}+\sum_{s \in \Omega} p^{s^{\prime}} z_{1}^{s^{\prime}} \leq 0 ; \forall S
\end{aligned}
$$

In the above terms $p^{s}$ the probability of the scenario s.

\section{SOLVING APPROACH}


To solve the model must be able to objective function without scale to solve it. The desired objective function of two criteria above is achieved. These criteria are not in a scale and without the objective function is as follows.

$$
\operatorname{MinZ}=w_{1}\left(\frac{f_{1}-f_{1}^{+}}{f_{1}^{-}-f_{1}^{+}}\right)+w_{2}\left(\frac{f_{2}-f_{2}^{+}}{f_{2}^{-}-f_{2}^{+}}\right)
$$

That in above terms $w_{1}, w_{2}$ respectively, are the criteria weights $f_{1}, f_{2}$. These weights can be achieved, experts and decision-makers in the field of study.

In above terms $f^{-}$an upper limit, $f^{+}$is a lower limit to the desired standard. To obtain the $f^{-}$and $f^{+}$in this way, the first issue to be resolved with regard to each criterion alone, in this case, according to existing criteria, twice every problem solved is calculated for each of two standard $f_{1}, f_{2}$ that most relevant results for a $2 \times 2$ matrix shown in the following equation.

$$
\begin{aligned}
& f_{1} \quad f_{2}
\end{aligned}
$$

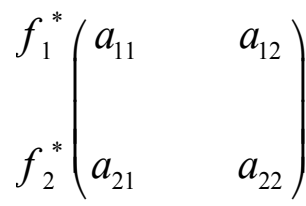

in the first row of the matrix above the condition that only by taking the standard $f_{1}$ model the desired problem is solved and row two in order to consider only the criterion of $f_{2}$ cases are solved. $f^{-}$and $f^{+}$ are calculated values are as follows.

$$
\begin{aligned}
& f_{1}^{+}=a_{11} \\
& f_{2}{ }^{+}=a_{22} \\
& f_{1}^{-}=a_{21} \\
& f_{2}{ }^{-}=a_{12}
\end{aligned}
$$

Finally the objective function can be written as follows:

$$
\operatorname{MinZ}=w_{1}\left(\frac{f_{1}-f_{1}^{+}}{f_{1}^{-}-f_{1}^{+}}\right)+w_{2}\left(\frac{f_{2}-f_{2}^{+}}{f_{2}^{-}-f_{2}^{+}}\right)
$$

\section{RESULTS OF THE STUDY}

\section{SOLVING THE MODEL WITH REAL DIMENSIONS}

In this study, 51 stations that the issue under consideration is viewed as nodes. Each of these nodes have the ability hub of that cost of setting up the hub in each hub in the table given below. In this research 
capacity of hub three scenarios is intended to consider these three scenarios simultaneously their average costs and variability is minimized. Also on the second purpose yaw rate of the minimum delivery time.

Table 3. data of railway

\begin{tabular}{|c|c|c|c|c|}
\hline Cost of launching & $\begin{array}{c}\text { Distance of } \\
\text { Tehran }\end{array}$ & $\begin{array}{c}\text { Name of } \\
\text { hub }\end{array}$ & $\begin{array}{l}\text { Name of } \\
\text { station }\end{array}$ & Row \\
\hline 100 & 0 & & Tehran & 1 \\
\hline 34 & 144 & Azarbaijan & Qazvin & 2 \\
\hline 32 & 315 & Azarbaijan & Zanjan & 3 \\
\hline 14 & 439 & Azarbaijan & Miyaneh & 4 \\
\hline 13 & 607 & Azarbaijan & Maragheh & 5 \\
\hline 80 & 736 & Azarbaijan & Tabriz & 6 \\
\hline 10 & 767 & Azarbaijan & Soufian & 7 \\
\hline 96 & 882 & Azarbaijan & Jolfa & 8 \\
\hline 21 & 887 & Azarbaijan & Salmas & 9 \\
\hline 16 & 958 & Azarbaijan & Razi & 10 \\
\hline 42 & 114 & Khorasan & Garmsar & 11 \\
\hline 28 & 228 & Khorasan & Semnan & 12 \\
\hline 17 & 364 & Khorasan & Damghan & 13 \\
\hline 74 & 429 & Khorasan & Shahroud & 14 \\
\hline 12 & 593 & Khorasan & Azadvar & 15 \\
\hline 6 & 655 & Khorasan & Naghab & 16 \\
\hline 20 & 718 & Khorasan & Sabzevar & 17 \\
\hline 19 & 788 & Khorasan & Neishabour & 18 \\
\hline 8 & 888 & Khorasan & Fariman & 19 \\
\hline 43 & 926 & Khorasan & Mashhad & 20 \\
\hline 110 & 1045 & Khorasan & Sarakhs & 21 \\
\hline
\end{tabular}

Submit Date: 10.05.2016, Acceptance Date: 25.06.2016, DOI NO: 10.7456/1060JSE/004 
The Turkish Online Journal of Design, Art and Communication - TOJDAC July 2016 Special Edition

\begin{tabular}{|c|c|c|c|c|}
\hline 80 & 167 & Khouzestan & Qom & 22 \\
\hline 65 & 307 & Khouzestan & Arak & 23 \\
\hline 11 & 453 & Khouzestan & Doroud & 24 \\
\hline 18 & 662 & Khouzestan & Andimeshk & 25 \\
\hline 32 & 803 & Khouzestan & Ahvaz & 26 \\
\hline 56 & 914 & Khouzestan & Sarbandar & 27 \\
\hline 49 & 924 & Khouzestan & Khorramshhar & 28 \\
\hline 99 & 225 & Hormozgan & Kashan & 29 \\
\hline 17 & 289 & Hormozgan & Badroud & 30 \\
\hline 12 & 453 & Hormozgan & Sistan & 31 \\
\hline 16 & 495 & Hormozgan & Isfahan & 32 \\
\hline 140 & 539 & Hormozgan & Meibod & 33 \\
\hline 180 & 598 & Hormozgan & Yazd & 34 \\
\hline 13 & 715 & Hormozgan & Bafgh & 35 \\
\hline 7.5 & 873 & Hormozgan & Zarand & 36 \\
\hline 103 & 952 & Hormozgan & Kerman & 37 \\
\hline 6 & 1174 & Hormozgan & Bam & 38 \\
\hline 85 & 968 & Hormozgan & Sirjan & 39 \\
\hline 54 & 1156 & Hormozgan & Tazarj & 40 \\
\hline 160 & 1338 & Hormozgan & Bandar Abbas & 41 \\
\hline 3.4 & 203 & Golestan & Firouzkouh & 43 \\
\hline 2.9 & 286 & Golestan & Polsefid & 44 \\
\hline 10 & 334 & Golestan & QaemShahr & 45 \\
\hline 14 & 354 & Golestan & Sari & 46 \\
\hline 5 & 392 & Golestan & Rostamkala & 47 \\
\hline
\end{tabular}

Submit Date: 10.05.2016, Acceptance Date: 25.06.2016, DOI NO: 10.7456/1060JSE/004 
The Turkish Online Journal of Design, Art and Communication - TOJDAC July 2016 Special Edition

\begin{tabular}{|c|c|c|c|c}
11 & 414 & Golestan & Amir Abad & 48 \\
\hline 9.7 & 403 & Golestan & Behshahr & 49 \\
\hline 13 & 461 & Golestan & $\begin{array}{c}\text { Bandar } \\
\text { Torkman }\end{array}$ & 50 \\
\hline 8.9 & 496 & Golestan & Gorgan & 51 \\
\hline
\end{tabular}

To solve the desired problem three times to run the code. Once only with regard to the first purpose, in which case the values of $f_{1}{ }^{+}$and $f_{2}{ }^{-}$is obtained and once only with regard to the second objective function that in this case, the values obtained $f_{1}{ }^{-}$and $f_{2}{ }^{+}$. Finally for the ultimate implementation of the objective function is considered as follows.

That finally, final value objective function is obtained as follows:

Table 4. The results of final model solution

\begin{tabular}{|r|r|r|r|r|r|r|r}
\hline$f_{1}^{+}$ & $f_{1}^{-}$ & $f_{2}^{+}$ & $f_{2}^{-}$ & First function & $\begin{array}{r}\text { Second } \\
\text { function }\end{array}$ & Z & Solving time \\
\hline 45819959066 & 54905250983 & 2456.676 & 2930.239 & 48881922704 & 2633.836 & 0.711124 & 13068.552 \\
\hline
\end{tabular}

\section{DISCUSSION AND CONCLUSION}

The important issue in hub location is new facility location that has recently been the focus of many studies. Hub location issues generally arise in the network transport and communications. Role of a transition point plays axial point where incoming traffic from this source together and sent to the other focal point or the traffic is divided into several arteries that are directed towards other purposes. Because of the uncertainty in the current situation is one of the most difficult and the most important responsibilities of project managers are considering the uncertainties in modeling. How to insert the uncertainty in the model and solving different issues impact on the performance and success of the project is the main goal of the current study. Based on the mathematical model of this study, taking into account the capacity and the constraints, the multiple allocation has been posted, the limitations and the service level has been analyzed. Further, the introduced Mathematical model is validated by Gomez Software.

In the current study, the effectiveness of the written version of the model prepared by the Railways Organization of the Islamic Republic of Iran has been solved and the optimal locations for the hub are introduced and the rest of the points specified by the hub connected to the hub. Finally, a network hub has been shown schematically.

Obtained results of These is that the desired average is considered the center of $1,6,19,22,34$. It should be noted objective functions are equal to 0.5 meters is considered. This means that two objectives of equal importance. If the decision maker can vary the degree of importance of objective functions according to 
the relative importance that attaches weights to change. Obtained results schematically in Figure 1 is shown.

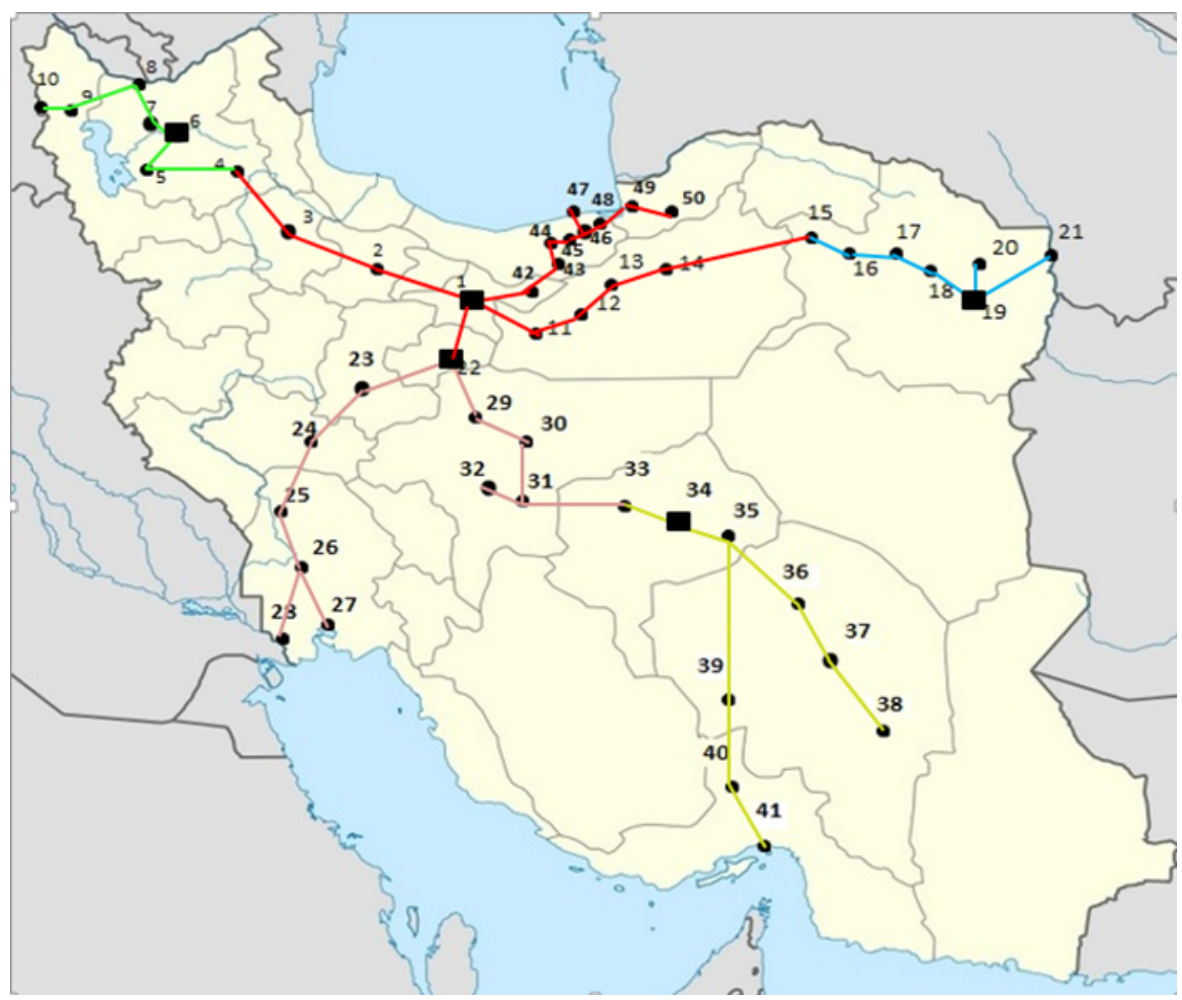

Figure 1. Hub

\section{REFERENCES:}

All the Citations and References have been sorted Alphabetically here and also shown by Brackets. They have also been corrected inside the paper.

Bashiri, Tavakoli Moghadam, Yazdi (2013) - problem location a period of uncertainty with regard to the possible limitation of hierarchical hub for travel time grid - second National Conference on Industrial Engineering and Systems - Iran - Najaf Abad (IAU )

Bozorgi, Torkestani, Serajian - (2013) - hierarchical hub location with capacity constraints and delivery time - Tenth International Conference on Industrial Engineering - Iran, Tehran (Tehran University) Campbell -(1992) - Location and allocation for distribution systems with transshipments and transportation economies of scale- Annals of Operations Research ,40, 77-99.

Contreras,Cordeau,Laporte - (2011)- Stochastic uncapacitated hub location - European Journal of Operational Research 212 (3), 518-528.

Davari,zarandi - (2013) - the single- allocation hierarchical hub median location problem with fuzzy demands - African Journal of business management,vol-195,165-181.

Eydi,Mirakhorli - (2012) - Hybrid heuristic method based on genetic algoritm for the convering problem under Fuzzy environment - international Journal of industrial,Engineering \& production management.

Fukushima, Sasaki - (2003) - On the hub-and-spoke model with arc capacity constraints - Journal of the Operations Research Society of Japan 46 (4), 409-428.

Ghasemi - (2013) - robust optimization model for problem hub has the capacity to location and stream coverage - Quarterly Management - Year I - Number 32. 
Habibzadeh Boukani- (2014) - Robust optimization approach to capacitated single and multiple allocation hub location problems - Sociedade Brasileira de Matemática Aplicada e Computacional Huang,WANG - (2009) - Robust Optimization of Hub-and-Spoke Airline Network Design Based on Multi-Objective Genetic Algorithm - Journal of Transportation Systems Engineering and Information Technology, 9(3), 86-92.

Jelodari - (2013) - model and solving location - routing capacity for a period of two objective - Thirteenth International Conference on Transportation and Traffic Engineering - Iran - Tehran (Department and Transport and Traffic)

Makui, Rostami, Jahani, Nikui- (2012) - A multi-objective robust optimization model for the capacitated P-hub location problem under uncertainty - Management Science Letters 2, 525-534.

Mohammadi,Jolai \& Rostami (2011) - An M/M/c queue model for hub covering location problem Mathematical and Computer Modelling, 54, 2623-2638.

Mohammadi , Torabi , Tavakkoli-Moghaddam - (2014) Sustainable hub location under mixed uncertainty - Transportation Research Part E 62, 89-115.

O'Kelly - (1987) - A quadratic integer program for the location of interacting hub facilities - European Journal of Operational Research 32, 393- 404.

Rostami , farahani - (2012)- Astochastic capacitated p-hub location problem - A Case study of Iran, 620628.

Serra, Marianov -(2003)- Location models for airline hubs behaving as M/D/c queues- Computers \& Operations Research, 30 (7), 983-1003.

Sim,Lowe,Thomas - (2009) - The stochastic p-hub center problem with service-level constraints Computers \& Operations Research 36 (12), 3166-3177.

Yaman,Carello - Solving the hub location problem with modular link capacities - Computers \& Operations Research 98 (78).

Yang-(2009)- Stochastic air freight hub location and flight routes planning- Applied Mathematical Modelling 33 (12), 4424-4430.

Yu, Li - (2000)-A robust optimization model for stochastic logistic problems, Int. J. Prod. Econ, 64, 385397. 